\title{
Experimental Study on Nonlinear Characteristics of Permeability and Compressibility of Soft Clay
}

\author{
Chang-xi YUE ${ }^{1,2,3,4 *}$, Zhi-jun CHEN ${ }^{1,2,3,4}$, Xiao-qiang KOU ${ }^{1,2,3,4}$, Dao-kun ZHUANG ${ }^{5}$, and Jiang-xin LU ${ }^{5}$ \\ ${ }^{1}$ CCCC Tianjin Port Engineering Institute Co., Ltd., Tianjin 300222, China \\ ${ }^{2}$ CCCC First Harbour Engineering Co., Ltd., Tianjin 300461, China \\ ${ }^{3}$ Key Laboratory of Port Geotechnical Engineering of Ministry of Communications, Tianjin 300222, China \\ ${ }^{4}$ Key Laboratory of Port Geotechnical Engineering of Tianjin, Tianjin 300222, China \\ ${ }^{5}$ School of Civil Engineering, Tianjin University, Tianjin, 300072, China
}

\begin{abstract}
Consolidation and permeability tests were conducted on soft clays with different liquid limit by GDS consolidation apparatus. Some fitting parameters were studied for 4 common nonlinear permeability models based on the test data. But different soil samples have different parameters for the same model. In order to find the universal law of permeability coefficient and compressibility with the soil property and void ratio, the void ratio was normalized by the liquid void ratio eL, and the relationship of e/eL with $\log k$ v and $\log p$ were established based on the test data. The Chapman-Richard curve fitting model was adopted to best fit the obtained time-compression data. The relationship between e/e w with logkv was further verified using 30 groups of test data of permeability collected from China and abroad. The relationship between e/eL with logp was also discussed in this paper, and the fitted curves and nonlinear equations was further simplified into two linear equations at the point of $\mathrm{e} / \mathrm{e}_{\mathrm{L}}=0.9$ so as to consistent with the well-known theory. The nonlinear equations can be used to calculate the permeability and compressibility according to the void ratio and liquid limit.
\end{abstract}

\section{Introduction}

Soft clay, especially sprayed landfill mud clay, has a high moisture content with large pores at the initial stage. In the consolidation process, the void ratios of the permeability coefficient and the compression coefficient decrease, and the effective stress increases, which shows a non-linear trend. According to the basic assumptions of conventional consolidation theory that transmission coefficient and compression coefficient are constants, the assumptions are not consistent to actual situation.

A lot of researches have been conducted on the nonlinear relationship between void ratio and permeability coefficient of soft clay. Xie Kanghe et al. ${ }^{[1]}$ discussed four nonlinear permeability models and the soil parameters of the four models through onedimensional consolidation permeability tests. Deng Yuebao et al. ${ }^{[2]}$ proposed a parameter selection method of soil compression nonlinear and seepage nonlinear models which has been universally recognized. Qi Tian et al. ${ }^{[3-4]}$ has proved the nonlinear relationship $e-\log p$ between void ratio and effective stress, and the nonlinear relationship $e-\log k_{v}$ between void ratio and permeability coefficient.

Some scholars have studied the measurement of the permeability coefficient of blow mud and the nonlinear permeability characteristics. For example, Zhang Ming et al. ${ }^{[5-6]}$ conducted a consolidation and permeability test on the pouring mud with a moisture content of more than $100 \%$ in Qianwan, Shenzhen. Scholars at home and abroad have also conducted some researches on compression nonlinearity ${ }^{[7-8]}$. All these consolidation and permeability studies are conducted on the same liquid limit soil, but for soil with different liquid limits, consolidation permeability tests should be conducted with different void ratios. Therefore, these studies lack universality.

Many researchers at home and abroad have conducted relevant studies on the predictive formulas of clay compressibility and permeability. Najaraj ${ }^{[9-12]}$ found that the soil permeability coefficient has nothing to do with the consolidation state, but only with e/eL. Achari and Joshi ${ }^{[13]}$ proposed a predictive formula for soil permeability coefficient with a liquid limit range of $40 \%$ to $60 \%$. Existing studies (Horpibulsuk ${ }^{[14-17]}$ ) are mostly conducted via curve fitting method based on onedimensional consolidation penetration test. By establishing the linear relationship between $e / e_{L}$ and $\log p$ with $\log k_{v}$ (Najaraj $\left.{ }^{[9-12}\right]$, Horpibulsuk ${ }^{[14-17]}$ ), researches (Horpibulsuk $^{[14-17]}$, Yamadera ${ }^{[18]}$ ) pointed out that the linear predictive relationship of permeability coefficient is not only suitable for undisturbed soil, but also for remolded soil. According to the above literature review, how to accurately establish a compressibility and permeability calculation method that has a wide range of applications and can consider both soil quality and void

* Chang-xi YUE: yuechangtab@163.com 
ratio is an important issue for studying soil compressionpermeability characteristics.

In this paper, consolidation and permeability tests were continuously conducted on dredger soil with different liuquid limit by GDS donsolidation apparatus, and the relationship between the permeability coefficient and void ratio as well as the relationship between the void ratio and the consolidation pressure were obtained. The liquid limit void ratio $e_{L}$ was used to normalize the test data, so as to explore general change law of compressibililty and permeability due to soil quiality and void ratio and to establish the fitting relationships between $e / e_{L}$ and $k_{v}$ as well as $p$.

\section{Consolidation-permeability test of dredged fill}

\subsection{Test soil samples and instruments}

The test soil samples were taken from Tianjin Xinjiang Port Area (TJDG), Nangang Landfill Area (TJNG), and Lingang Landfill Area (TJLG). Configure the dredged fills in different areas with different initial water contents, and perform liquid limit and plastic limit tests on the dredged fills from the three areas at the same time. The physical indexes of soil samples are shown in Table 1.

Table 1. Primary physical parameters of test soils

\begin{tabular}{|c|c|c|c|c|}
\hline $\begin{array}{c}\text { Soil } \\
\text { sample } \\
\text { No. }\end{array}$ & $w_{0}(\%)$ & $G_{\mathrm{s}}$ & $w_{L}(\%)$ & $w_{p}(\%)$ \\
\hline TJDG & 64.85 & 2.72 & 46.75 & 23.59 \\
\hline TJNG & 112.07 & 2.70 & 50.25 & 22.90 \\
\hline TJLG & 95.85 & 2.72 & 41.50 & 17.50 \\
\hline
\end{tabular}

The GDS Advanced Consolidation Testing System (GDS Advanced Consolidation Testing System), a consolidation-permeability test system produced by British GDS, was used in the tests. Figure 1 shows the GDS consolidation penetration test system.

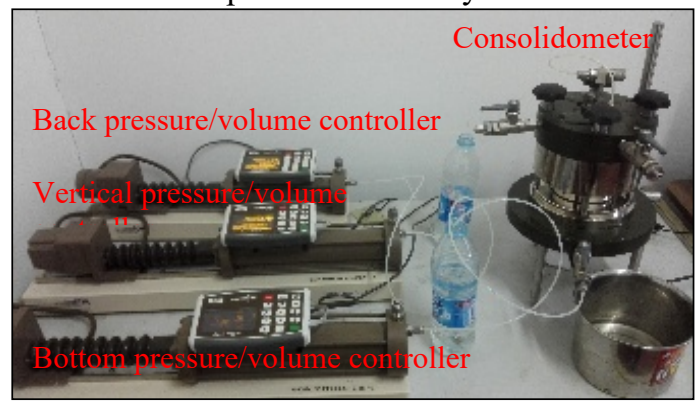

\subsection{Test plan and process}

The initial physical indicators of the test soil samples are shown in Table 1. Coat the soil sample on the ring cutter, install the pressure chamber, exhaust the air remaining in the pressure chamber and the channel, and finally conduct the consolidation-permeability test. The penetration test is carried out with a constant head $\triangle h$. When the initial water content is higher, the penetration rate is faster, and the following application methods are used to prevent fine particles from flowing in the seepage. As shown below, when the consolidation stress is lower than $10 \mathrm{kPa}$, the head difference $\triangle h=4-8 \mathrm{kPa}$; when the consolidation stress is $10 \mathrm{kPa}<\mathrm{P}<50 \mathrm{kPa}, \triangle$ $h=8-15 \mathrm{kPa}$; when the consolidation stress $\mathrm{P}>50 \mathrm{kPa}, \triangle$ $h=15-25 \mathrm{kPa}$.

For the same consolidation pressure $p$, set multiple constant head differences $\Delta h$, measure the permeability coefficient in each head difference, and compute the average permeability coefficients corresponding to the consolidation pressure $p$. The test plan is shown in Table 2.

Table 2. Test scheme

\begin{tabular}{|c|c|c|c|}
\hline Soil sample No. & $\begin{array}{c}\text { Consolidation } \\
\text { pressure } \\
(\mathrm{kPa})\end{array}$ & $\begin{array}{c}\text { Void } \\
\text { ratio } \\
e\end{array}$ & $\begin{array}{c}\text { Permeability } \\
\text { coefficient } \\
\left(10^{-6} \mathrm{~cm} / \mathrm{s}\right)\end{array}$ \\
\hline \multirow{3}{*}{ TJLG/TJNG/TJDG } & $p_{1}$ & $e_{1}$ & $k_{1}$ \\
\cline { 2 - 4 } & $p_{2}$ & $e_{2}$ & $k_{2}$ \\
\cline { 2 - 4 } & $\ldots$ & $\ldots$ & $\ldots$ \\
\hline
\end{tabular}

\section{Test analysis}

\subsection{Test soil samples and apparatus}

According to the test plan in Table 2, consolidationpermeability tests were carried out on the soil samples with three liquid limits. Test results were shown in Table 3.

Fig. 1. GDS one-dimensional consolidation testing system

Table 3. Permeability test results of Tianjin dredged fill

\begin{tabular}{|c|c|c|c|c|c|}
\hline \multirow{3}{*}{ Soil sample No. } & \multirow{2}{*}{$w_{0}(\%)$} & \multirow{3}{*}{$e_{0}$} & $\begin{array}{c}\text { Consolidation } \\
\text { pressure } \\
(\mathrm{kPa})\end{array}$ & Void ratio & $\begin{array}{c}\text { Permeability } \\
\text { coefficient }\left(10^{-}\right. \\
6 \mathrm{~cm} / \mathrm{s})\end{array}$ \\
\hline \multirow{3}{*}{ TJDG } & \multirow{4}{*}{64.85} & \multirow{4}{*}{1.764} & 7 & 1.593 & 0.295 \\
\cline { 4 - 5 } & & 10 & 1.586 & 0.305 \\
\cline { 3 - 5 } & & 20 & 1.305 & 0.116 \\
\cline { 3 - 5 } & & 30 & 1.208 & 0.088 \\
\cline { 3 - 5 } & & 80 & 0.955 & 0.051 \\
\cline { 3 - 5 } & & 150 & 0.892 & 0.029 \\
\hline
\end{tabular}




\begin{tabular}{|c|c|c|c|c|c|}
\hline & & & 200 & 0.855 & 0.028 \\
\hline & & & 300 & 0.796 & 0.018 \\
\hline \multirow{9}{*}{ TJLG } & \multirow{9}{*}{95.85} & \multirow{9}{*}{2.388} & 2 & 1.817 & 2.275 \\
\hline & & & 5 & 1.648 & 1.413 \\
\hline & & & 10 & 1.485 & 0.463 \\
\hline & & & 15 & 1.365 & 0.298 \\
\hline & & & 30 & 1.197 & 0.186 \\
\hline & & & 50 & 1.060 & 0.112 \\
\hline & & & 80 & 0.914 & 0.074 \\
\hline & & & 150 & 0.817 & 0.032 \\
\hline & & & 300 & 0.697 & 0.024 \\
\hline \multirow{10}{*}{ TJNG } & \multirow{10}{*}{112.07} & \multirow{10}{*}{3.026} & 2 & 2.640 & 1.598 \\
\hline & & & 5 & 2.178 & 1.284 \\
\hline & & & 10 & 1.930 & 0.455 \\
\hline & & & 15 & 1.746 & 0.343 \\
\hline & & & 30 & 1.535 & 0.168 \\
\hline & & & 50 & 1.390 & 0.130 \\
\hline & & & 80 & 1.231 & 0.089 \\
\hline & & & 150 & 1.119 & 0.039 \\
\hline & & & 240 & 1.103 & 0.025 \\
\hline & & & 300 & 1.066 & 0.018 \\
\hline
\end{tabular}

\subsection{Analysis of nonlinear permeability model parameters}

According to existing research, there are four common nonlinear relationships between void ratio and permeability coefficient of soft clay:

(1) The permeability formula of $e-\lg k_{\mathrm{v}}$ model ${ }^{[19]}$ is $e=e_{0}+C_{k} \log k_{\mathrm{v}}$, wherein $e_{0}$ is the void ratio and $C_{\mathrm{k}}$ is the permeability index;

(2) The permeability formula of $\lg e-\lg k_{\mathrm{v}}$ model ${ }^{[20]}$ is $\lg e=A \lg k_{\mathrm{v}}+B$, where $\mathrm{A}$ and $\mathrm{B}$ are permeation characteristic parameters;

(3) The nonlinear permeability formula of $\lg \left[k_{\mathrm{v}}(1+e)\right]-\lg { }^{[21]}$ model is $\lg \left[k_{\mathrm{v}}(1+e)\right]=\lg C+n \lg e$, wherein $C$ is the reference permeability reflecting the permeability characteristics of the soil, the unit is $\mathrm{cm} / \mathrm{s}, \mathrm{n}$ is the material parameter of the soil;

(4) The permeability formula of $\lg (1+e)-\lg k_{v}$ model [ ${ }^{[7]}$ is $\lg (1+e)=\alpha \lg k_{\mathrm{v}}+\beta$, wherein $\alpha$ and $\beta$ are soil parameters.

The four non-linear permeability models are used to comprehensively analyze all test data, and the fitting curve is shown in Figure 2. Based on the fitting curve, the fitting parameters of the four permeability models of the test soil are determined. The fitting results are shown in Table 4.

Table 4 shows that the fitting correlation coefficients of the four permeability models are all above 0.9 , that is, all the four nonlinear permeability models are suitable for the three liquid-limit dredged silt. However, it can be seen from the model parameters that in $e$ - $\lg k_{\mathrm{v}}$ model and for clay with different liquid limits, soil parameter $e_{0}$ is between 5.3 and 7.4, and the value of $C_{k}$ is between 0.59 and 0.86 , indicating that the calculation parameters of different liquid limit clays are different. The same with the other three models, there are difference in the two parameters of the clay with different liquid limits. Among them, the $\lg e-\lg k_{\mathrm{v}}$ model has the smallest difference. After uniformly fitting the test data of the soft clay with different liquid limits, the results show that the comprehensive analysis parameters of the four models are quite different from the fitting parameters of each soil quality, and their correlation coefficients are also low.
In summary, the clay model with different liquid limits and the nonlinear permeability model are not a one-to-one mapping relationship. That is, the permeability characteristics of different clays correspond to different parameters. At present, the soil permeability coefficient is obtained through permeability test, and it is necessary to establish a predictive relationship for the permeability coefficient with a wide range of applications, high accuracy, and representativeness.

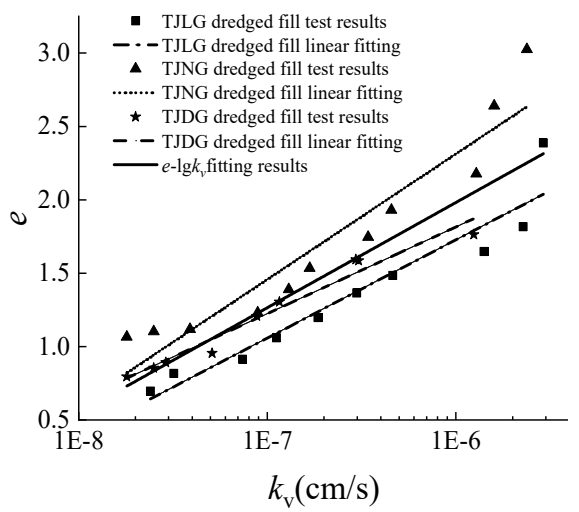

(a) $e-\lg k$ permeability relationship

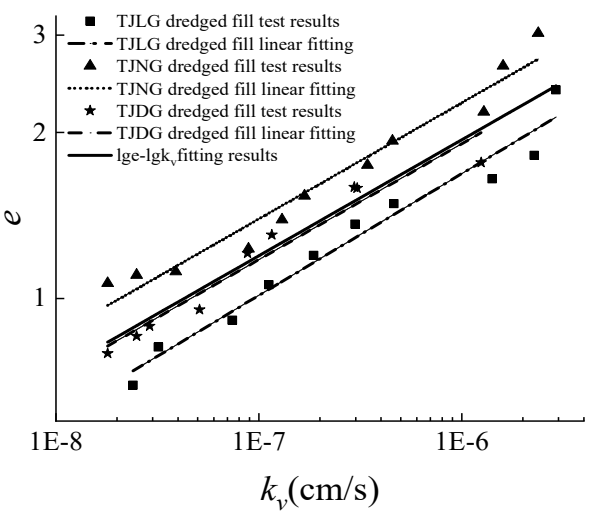

(b) $\lg e-\lg k_{\mathrm{v}}$ permeability relationship 


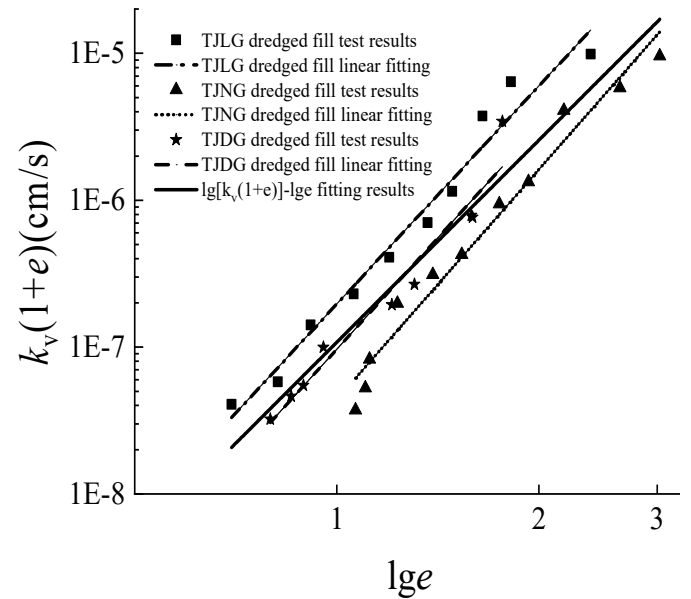

(c) $\lg \left[k_{\mathrm{v}}(1+e)\right]-\lg e$ permeability relationship

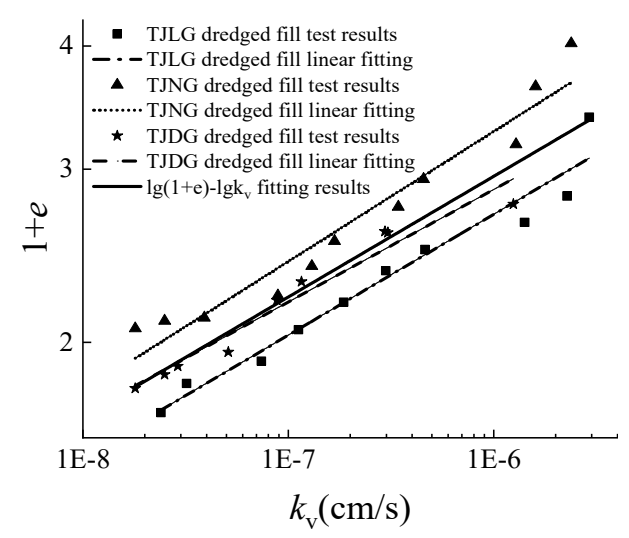

(d) $\lg (1+e)-\lg k_{\mathrm{v}}$ permeability relationship

Fig. 2. Analysis of nonlinear permeability relationships

Table 4. Fitting parameters and correlation coefficient $\mathrm{R}^{2}$

\begin{tabular}{|c|c|c|c|c|c|c|c|c|c|c|c|c|}
\hline \multirow{2}{*}{$\begin{array}{c}\text { Model } \\
\text { Parameter }\end{array}$} & \multicolumn{3}{|c|}{$e-\lg k_{\mathrm{v}}$} & \multicolumn{4}{|c|}{$\lg e-\lg k_{\mathrm{v}}$} & \multicolumn{3}{c|}{$\lg \left[k_{\mathrm{v}}(1+e)\right]-\lg e$} & \multicolumn{4}{c|}{$\lg (1+e)-\lg k_{\mathrm{v}}$} \\
\cline { 2 - 14 } & $e_{0}$ & $C_{\mathrm{k}}$ & $R^{2}$ & $A$ & $e_{0}$ & $C_{\mathrm{k}}$ & $R^{2}$ & $A$ & $e_{0}$ & $C_{\mathrm{k}}$ & $R^{2}$ & $A$ \\
\hline TJLG & 5.743 & 0.669 & 0.909 & 0.221 & 5.743 & 0.669 & 0.909 & 0.221 & 5.743 & 0.669 & 0.909 & 0.221 \\
\hline TJNG & 7.442 & 0.855 & 0.902 & 0.211 & 7.442 & 0.855 & 0.902 & 0.211 & 7.442 & 0.855 & 0.902 & 0.211 \\
\hline TJDG & 5.359 & 0.591 & 0.960 & 0.210 & 5.359 & 0.591 & 0.960 & 0.210 & 5.359 & 0.591 & 0.960 & 0.210 \\
\hline All & 6.283 & 0.717 & 0.781 & 0.210 & 6.283 & 0.717 & 0.781 & 0.210 & 6.283 & 0.717 & 0.781 & 0.210 \\
\hline
\end{tabular}

\section{Nonlinear relationship of the $k_{v}-e / e_{L}$ model}

In this paper, the liquid limit void ratio is used as the control index, the parameter $e / e_{L}$ is introduced, and the normalized analysis is used to explore the universal law of the soil permeability coefficient that can be used to express both the void ratio and the liquid limit, that is, to establish the normalized corresponding relationship between permeability coefficient and the void ratio, which is shown in Figure 3 The relationship between $e$ and $k_{v}$ of the dredged fill is shown in Figure4.

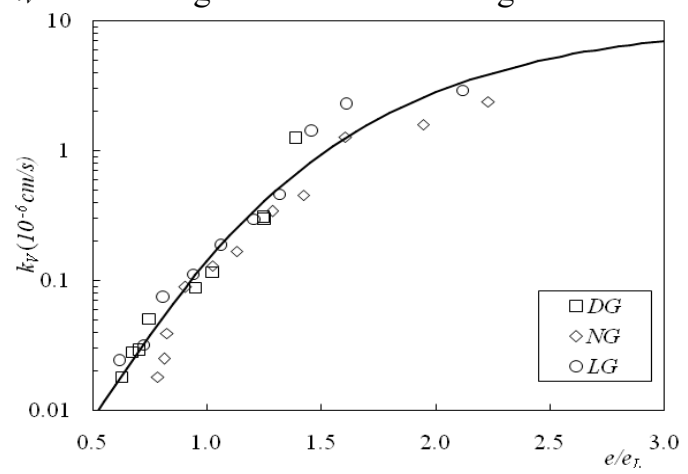

Fig. 3. Normalized behavior of the permeability results

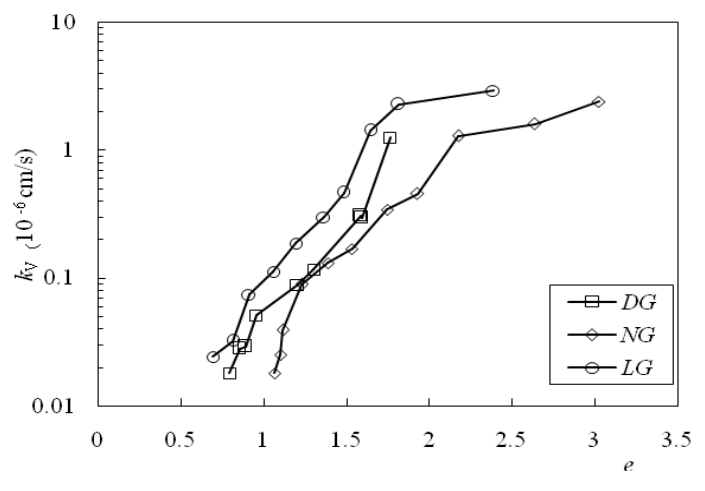

Fig. 4. $e-\lg k_{v}$ curves

Comparing Figures 3 and 4 , there is a nonlinear relationship between $e / e_{\mathrm{L}}$ and $\lg k_{\mathrm{v}}$, and the nonlinearity is more significant when the permeability coefficient $\mathrm{k}_{\mathrm{v}}>10^{-6} \mathrm{~cm} / \mathrm{s}$. The test points normalized by $e / e_{L}$ are concentratedly distributed on both sides of a smooth curve, and show an obvious growing trend. Since the normalized $e-k_{\mathrm{v}}$ test data is concentrated on a data belt, which conforms to the law of the growth curve, so it can be described by a growth model.

The mathematical expression of Chapman-Richard's (Ratkowsky, 1990) growth curve model is $y=\delta\left(1-\mathrm{e}^{-\mu x}\right)^{\lambda}+\varepsilon$, wherein $\delta$ is the limit value of $y$ when $x$ tends to infinity; $\varepsilon$ is the initial value of $y$ when $x$ is zero; $\lambda$ and $\mu$ are the fitting parameters; $e$ is the Napierian base. The physical meanings $\delta$ and $\varepsilon$ are shown in Figure 5, and $\delta$ can be negative, indicating that with the increase of $x$, the value of $y$ decreases to $\varepsilon-\delta$. 


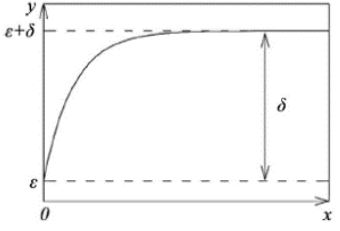

(a) $\delta>0$

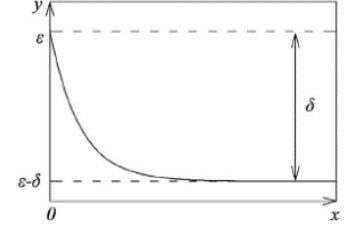

(b) $\delta<0$
Fig. 5. Illustration of Chapman-Richard model

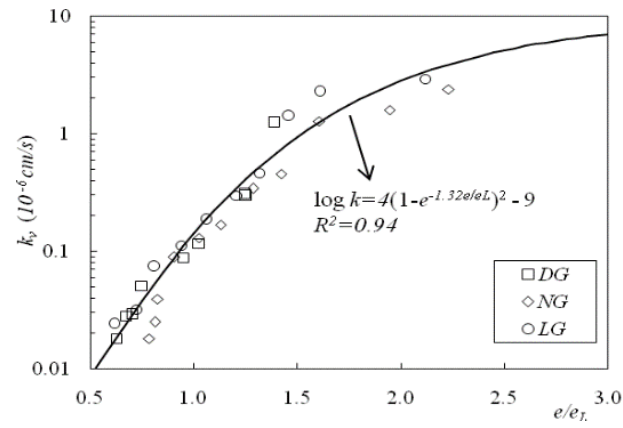

Fig. 6. $k_{v}-e / e_{L}$ relationships based on Chapman-Richard model

The growth curve model is used to fit and analyze the normalized data, as shown in Figure 6. The correlation coefficient is 0.94 , and the fitting equation is:

$$
\log k_{v}=4\left(1-e^{-1.32 e / e_{L}}\right)^{2}-9
$$

For saturated soft clay:

$$
e_{L}=G_{s} \cdot w_{L}
$$

According to (1) and (2), the fitting equation of permeability coefficient of the dredged fill that considers the void ratio and liquid limit is obtained:

$$
\log k_{v}=4\left[1-\exp \left(-1.32 e /\left(G_{s} \cdot w_{L}\right)\right)\right]^{2}-9
$$

Consult the literature (Zeng et al. ${ }^{[16]}$, Cai Chao et al. ${ }^{[17]}$, Li Youyun et al. ${ }^{[18]}$, Najaraj ${ }^{[9-10]}$, Siddique ${ }^{[19]}$, Pane et al. ${ }^{[20]}$, Znidarcic ${ }^{[21]}$, Sivakumer ${ }^{[22]}$, Fox et al. ${ }^{[23]}$, collect and sort out 30 sets of permeability test data including this test, and plot the relationship diagram of void ratio and permeability coefficient, as shown in Figure 7. The liquid limit of different soil quality $w_{\mathrm{L}}$ and the specific gravity $G_{\mathrm{s}}$ of soil particles are shown in the legend of Figure 7.

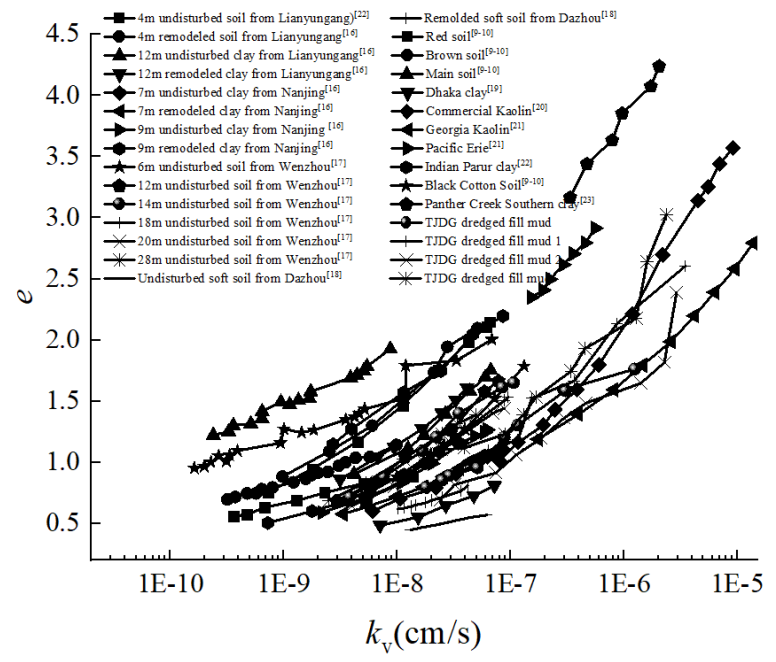

Fig. 7. $e-k_{v}$ relationships of different clays
Figure 7 shows that the distribution of $e-k_{\mathrm{v}}$ test points for clays with different liquid limits is relatively discrete. Use the parameter $e / e_{\mathrm{L}}$ to normalize the collected test data, establish the corresponding relationship between the normalized permeability coefficient and the void ratio, and analyze its applicability through formula (1), as shown in Figure 8.

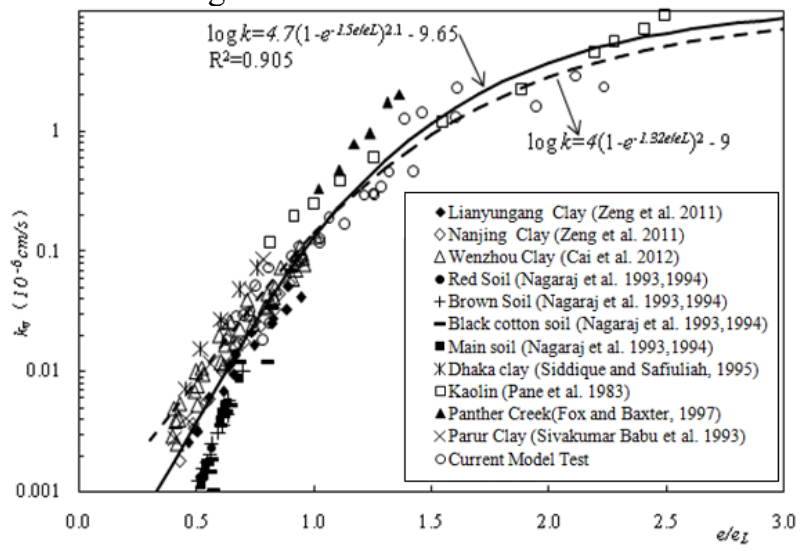

Fig. 8. $k_{v}-e / e_{L}$ relationships based on Chapman-Richard model

As shown in Figure 8, formula (1) is biased in a general sense. Formula (1) is obtained by fitting the results of the permeability test of Tianjin dredged fill. To this end, the growth curve model is used to fit and analyze the test data, as shown in Figure 8.

It can be seen from Figure 8 that the collated permeation test data is relatively concentrated after $e / e_{\mathrm{L}}$ normalization, showing an obvious data band. The growth model is used to fit and analyze all the data, the correlation coefficient is 0.905 , and the fitting formula is as follows:

$$
\log k_{v}=4.7\left(1-e^{-1.5 e / e_{L}}\right)^{2}-9.65
$$

From formulas (2) and (4), the following formula can be obtained:

$$
\log k_{v}=4.7\left[1-\exp \left(-1.5 e /\left(G_{s} \cdot w_{L}\right)\right)\right]^{2}-9.65
$$

The difference between formulas (3) and (5) is very small. The method of analyzing the permeability coefficient of dredged fill based on the growth curve is correct, and formula (5) is more universal. It can be seen from formula (5) that there are only two parameters in the permeability coefficient formula obtained based on growth model, and the permeability coefficient of the soil with different void ratios can be calculated by the liquid limit index. The liquid limit involved in the regression equation is between $40 \%$ and $120 \%$, the void ratio is between 0.5 and 4.5 , and $e / e_{\mathrm{L}}$ is between 0.3 and 2.5. The correlation and significance level are good, and the application range is wide. Formula (5) is recommended as the final predictive formula for permeability coefficient.

\section{Analysis of nonlinear compression characteristics of mud dredged fill}

The e-lgp compression curve of dredged silt is shown in Figure 9. The e-lgp curve of dredged silt has an inflection point before and after point where the 
consolidation stress is $50 \mathrm{kPa}$. The void ratio at the inflection point is close to the liquid-limit void ratio, which is the junction point of solid and liquid soil. That is, the nonlinear characteristics of dredged fill in the two states are significantly different in compression.

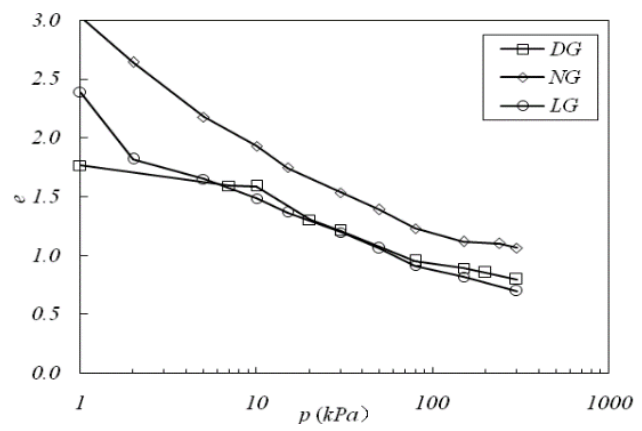

Fig. 9. $e-\lg p$ curves

The parameter $e / e_{\mathrm{L}}$ is introduced to normalize the compression test data, and the growth model is used to perform fitting analysis on the normalized data, as shown in Figure 10. The correlation coefficient is 0.926 , and the fitting equation is:

$$
e / e_{L}=-1.4\left(1-\exp ^{-\log p}\right)^{2}+1.86
$$

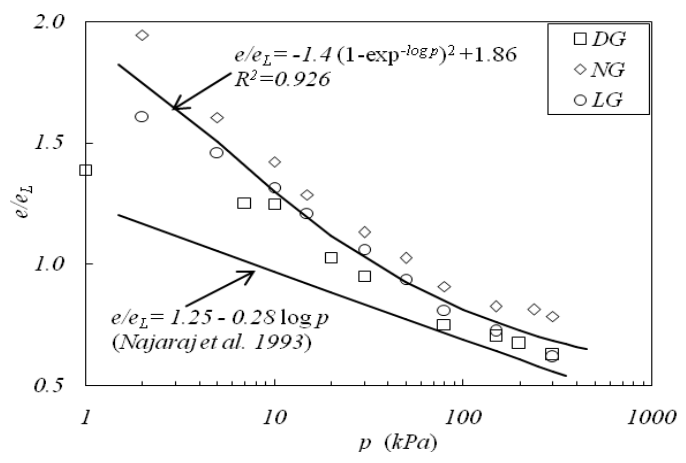

Fig. 10. Test results and curve fitting of compressibility

After normalization, the relationship between $e / e_{\mathrm{L}}$ and $\log p$ is no longer a strict linear relationship, and an inflection point appears under a certain consolidation stress. It can be seen from the Nagaraj linear equation in the figure that the current linear method is not suitable for the dredged silt with high water content, especially when the consolidation pressure is less than 10kpa, there is a significant deviation. In order to simplify the relationship between $e / e_{\mathrm{L}}$ and $\log p$, the curve can be divided into two straight lines, as shown in Figure 11. The intersection point of the two straight lines is $e=0.9 e_{\mathrm{L}}$, which is basically close to the liquid limit. When $e / e_{\mathrm{L}}<0.9$, the relationship between $e / e_{\mathrm{L}}$ and $\log p$ can be described as in equation (7), when $e / e_{\mathrm{L}}>0.9$, the relationship between $e / e_{\mathrm{L}}$ and $\log p$ can be described as in equation (8).

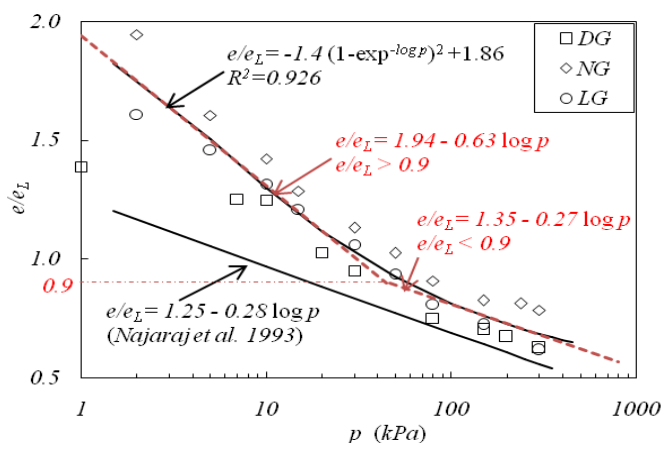

Fig. 11. Analysis of compressibility

$$
\begin{aligned}
& e / e_{L}=1.35-0.27 \log p\left(e / e_{\mathrm{L}}<0.9\right) \\
& e / e_{L}=1.94-0.63 \log p\left(e / e_{\mathrm{L}}<0.9\right)
\end{aligned}
$$

As shown in Figure 11, for under-consolidated dredged fill with high water content, the liquid limit water content is the demarcation point. When the soil moisture content is greater than the liquid limit, there is a nonlinear relationship. That is, the compression characteristics of soil cannot be expressed by the same straight line.

\section{Conclusion}

In this paper, the GDS consolidation apparatus is used to carry out consolidation-permeability joint tests on the dredged fill with different liquid limits. On this basis, domestic and foreign test data are collected and sorted, and the following results and conclusions are obtained by using mathematical statistics and model parameter research.

(1) Through indoor consolidation-permeability tests of soft clay with different liquid limits, the calculation parameters of four permeability models are obtained. The model parameters of liquid-limit clay are not unique, so the parameter of a certain soil cannot be used to describe the permeability characteristics of all soft clay.

(2) Establish the $k_{\mathrm{v}}-e / e_{L}$ relationship fitting curve. Based on the Chapman-Richard growth model, permeability coefficient with a wide application range and high accuracy is obtained. The permeability coefficient corresponds to void ratio and liquid limits.

(3) Based on the Chapman-Richard growth model, the $e / e_{L}-p$ relationship fitting curve is established, and two straight line equations are used to describe the compression characteristics of the under-consolidated dredged fill. The dividing point of the two straight lines is at the point where $e=0.9 e_{\mathrm{L}}$.

\section{References}

1. XIE Kang-he, QI Tian, HU An-feng, et al. Experimental study on nonlinear permeability characteristics of Xiaoshan clay based on GDS. Rock and Soil Mechanics, 29(2),420-424(2008), (in Chinese) 
2. DENG Yue-bao, XIE Kang-he, LI Fei-fei, LIU Ganbin. Nonlinear finite element analysis of consolidation for vertical drained ground with parameters determined from GDS consolidation permeability tests. Chinese Journal of Rock Mechanics and Engineering, 33(S2),4203-4210 (2014), (in Chinese)

3. QI Tian, XIE Kang-he, LI Xi-bin. Laboratory determination of one-dimensional nonlinear consolidation computational parameters of soft soil.Journal of Zhejiang University: Engineering Science, 40(8),1388-1392 (2006), (in Chinese)

4. QI Tian, XIE Kang-he, TANG Hu-le. Computational parameters on one-dimensional nonlinear sonsolidation of over-consolidation soil and its experimental determination. Chinese Journal of Engineering Geophysics, 5(6),735-741 (2008), (in Chinese)

5. ZHANG Ming, JIANG Min-min, ZHAO You-ming, et al. Nonlinear permeability and parameter determination for dredged fill based on GDS consolidation apparatus. Chinese Journal of Rock Mechanics and Engineering,32(3),625-632(2013), (in Chinese)

6. ZHANG Ming, WANG Wei, ZHAO You-ming, MA Donghui. Study on coefficient of consolidation of Dredged Fill based on GDS consolidation and permeability test. Journal of Beijing University of Technology, 38(8),1214-1219(2012),(in Chinese)

7. QI Tian. Theoretical and experiment studys on onedimensional nonlinear conso- lidation of soft soil. Hangzhou Zhejiang University, (2008), (in Chinese)

8. ZHUANG Hui-huang. Consolidation calculation of super-soft ground with vertical drains. Beijing Chinese Academy of Railway Sciences, (2009),(in Chinese)

9. Nagaraj T S, Pandian N S, Narasimha Raju P S R. Stress-state-permea- bilitre lationships for finegrained soils. Geotechnique;43(2),333-336 (1993)

10. Nagaraj T S, Pandian N S, Narasimha Raju P S R. Stress-state-permeability relationships for overconsolidated clays. Geotechnique, 44(2), 333-336 (1994)

11. Nagaraj TS, Miura N, Prakash Y, Yamadera A. Analysis of compressibility and permeability behaviour of soils with induced cementation. Proceedings of Indian Geotechnical Conference IGC-95, Bangalore, (1), 53-56 (1995)

12. Nagaraj TS, Pandian NS, Narasimha Raju PSR. Compressibility behavior of soft cemented soils. Geotechnique 48 (2), 281-287 (1998)

13. GOPAL ACHARI, JOSHI R C. A reexamination of the permeability index of clays: 1 Disussion. Canadian Geotechnical Journal, 31(1), 140-141 (1994)

14. Horpibulsuk S, Bergado DT, Lorenzo GA. Compressibility of cement admixed clays at high water content. Geotechnique 54 (2),151-154 (2004)
15. Horpibulsuk S, Miura N, Nagaraj TS. Assessment of strength development in cement-admixed high water content clays with Abrams' law as a basis. Geotechnique 53 (4),439-444 (2003)

16. Horpibulsuk S, Shibuya S, Fuenkajorn K, Katkan W. Assessment of engineering properties of Bangkok clay. Canadian Geotechnical Journal 44 (2),173-187 (2007)

17. Horpibulsuk S, Yangsukkaseam N, Chinkulkijniwat -AT, Du YJ. Compressibility and permeability of Bangkok clay compared with kaolinite and bentonite, Applied Clay Science, 52(1-2),150-159 (2011)

18. Yamadera A, Nagaraj TS, Miura N. Prediction of strength development in cement stabilized marine clay. Proceedings of Geotechnical Engineering Conference, Bangkok, Thailand, 141-153 (1998)

19. TAVENAS F, JEAN P, et al. The permeability of natural soft clays. Part II: peameability characteristic. Canadian Geotechnical Journal, 20(4), 645-659 (1983)

20. GHOLAMREZA M. Mechanisms the permeability of clays. Clay and Clay Mineral, 19(3), 151-158 (1971)

21. SAMARASINGHE M, HUANG Y H, DENEVICH V P. Permeability and consolidation of normally consolidated soils. Journal of the Geotechnical Engineering Division, ASCE, 108(6), 835-850. (1982)

22. Ling-Ling Zeng, Zhen-Shun Hong, Yuan-Qiang Cai, Jie Han. Change of hydraulic conductivity during compression of undisturbed and remolded clays. Applied Clay Science (2011)

23. CAI Chao, GAO Yu-feng, ZENG Ling-ling, HONG Zhen-shun, TAO Chong-fu. Change in hydraulic conductivity of natural clays during compression. Journal of Sichuan University (Engineering Science Edition), 44(S1),104-109(2012), (in Chinese)

24. LI Youyun, LIU Baojian, XIE Yongli. Influences of permeability and consolidation settlement on structure of soft clay. Chinese Journal of Rock Mechanics and Engineering, 25(S2), 3587-3592 (2006), (in Chinese)

25. SIDDIQUE A, SAFIULIAH A M M. Permeability characteristics of reconstituted Dhaka clay. Bangladesh Journal of the Civil Engineering Division,23(1),103-115 (1995)

26. PANE V, CROCE P, ZNIDARCIC D, et al. Effects of consolidation on permeability measurements for soft clay[J]. Geotechnique, 33(1), 67-72.(1983)

27. ZNIDARICIC D, SCIHIFFMAN D P, PANE V, etal. The theory of one-dimensional consilidation of saturated clays: part $\mathrm{V}$, constant rate of deformation testing and analysis. Geotechnique, 36(2),227-237 (1986)

28. SIVAKUMAR BABU G L, PANDIAN $\mathrm{N} S$, NAGARAJ $T$ S. A reexamination of the permeability index of clays. Canadian Geotechnical Journal, 30(1),187-191 (1983) 
29. FOX P J, BAXTER D P. Consolidation properties of soil slurries from hydraulic consolidation test. Geotechnical and Geoenvironmental Engineering, ASCE, 123(8),770-776 (1997) 